\title{
EMPREGO DA ARBORIZAÇÃO NA MELHORIA DO CONFORTO TÉRMICO NOS ESPAÇOS LIVRES PÚBLICOS
}

\author{
Juliana Cristina Augusto Shams ${ }^{1}$, Daniele Cristina Giacomeli ${ }^{2}$, Nivia Maria Sucomine ${ }^{3}$
}

(recebido em 12.11.2009 e aceito para publicação em 28.12.2009)

\begin{abstract}
RESUMO
A urbanização acelerada nos grandes centros tem incitado sérios danos à condição ambiental, bem como consideráveis prejuízos econômicos, sociais e de qualidade de vida às comunidades urbanas. Em se tratando da qualidade climatológica, nota-se significativo aumento da temperatura dos centros urbanos em relação às áreas rurais adjacentes, sendo este aumento apontado como efeito denunciador das alterações climáticas produzidas pelo ambiente construído, onde os grandes responsáveis por essas alterações são as diferenças existentes entre as características térmicas dos materiais de construção e da vegetação. A partir da análise de trabalhos relacionados aos espaços livres públicos e à arborização urbana, realizada neste artigo, nota-se que, referente aos aspectos do conforto humano as preferências, para realização de atividades, se voltam para ambientes confortáveis termicamente e que a presença da arborização urbana tem comprovado a eficiência para mitigar as temperaturas nos locais de maior concentração populacional, proporcionando estabilidade microclimática devido à redução das amplitudes térmicas, redução da insolação direta, ampliação das taxas de evapotranspiração e redução da velocidade dos ventos, desempenhando assim um importante papel na melhoria da condição ambiental das cidades e conseqüente melhora na qualidade de vida de seus habitantes, além de tornar mais efetiva a utilização dos espaços públicos.
\end{abstract}

Palavras-chave: árvores, qualidade climatológica, clima urbano, qualidade de vida

${ }^{1}$ Engenheira Agrônoma, Mestranda pelo Programa de Pós-graduação em Fitotecnia - ESALQ/USP; R. Pádua Dias, 11 - Piracicaba/SP - CEP: 13418-000; e-mail: <ju.shams@gmail.com>.

${ }^{2}$ Arquiteta, Mestranda pelo Programa de Pós-graduação em Engenharia Urbana - PPGEU/UFSCar, São Carlos, SP; <d_giacomeli@yahoo.com.br>.

${ }^{3}$ Ecóloga, Mestranda pelo Programa de Pós-graduação em Engenharia Urbana - PPGEU/UFSCar, São Carlos, SP; e-mail: <niviasucomine@yahoo.com.br>. 


\title{
THE USE OF AFFORESTATION FOR THE IMPROVEMENT OF THERMAL COMFORT IN OPEN PUBLIC SPACES
}

\begin{abstract}
The accelerated urbanization in large centers has prompted serious damage to the environmental condition and considerable economic, social and quality of life losses for urban communities. In the case of climatology quality, a significant increase in temperature of urban centers in comparison to adjacent rural areas is noted, this increase being pointed as a denouncing effect of climate change produced by the built environment, where the major responsible for these changes are the differences between the thermal characteristics of building materials and vegetation. From the analysis of works related to public spaces and urban afforestation, realized in this article, it is noted that, concerning the human comfort aspects, the preference, for carrying out activities, turns to thermally comfortable environments and the presence of urban afforestation has proven the efficiency to mitigate the temperatures in the highest concentration of local population, providing microclimatic stability due to the reduction of temperature range, reduction of direct sunlight, extension of the rates of evapotranspiration and the reduction of the speed of winds, thus playing an important role in improving the environmental condition of cities and consequent improvement in quality of life of its inhabitants, in addition to making more effective the use of public spaces.
\end{abstract}

Keywords: trees, thermal comfort, urban climate, quality of life. 


\section{Emprego da Arborização...}

\section{INTRODUÇÃO}

O desafio das grandes cidades é o crescimento e o desenvolvimento urbano que proporcionem geração de riqueza, qualidade de vida e qualidade ambiental para seus atuais e futuros habitantes. Esse é o princípio do desenvolvimento sustentável, o qual estabelece o meio ambiente como ponto comum e de equilíbrio entre a tecnologia e o progresso, na escala onde a vida acontece: o espaço urbano. (ARAUJO \& CARAM, 2006)

Contudo, devido ao aumento da população humana, até então em sua maioria rural, e o surgimento da industrialização em larga escala, na esperança de melhores condições de vida, houve um intenso fluxo de pessoas do campo para as cidades, que por falta de um planejamento adequado cresceram desordenadamente, alterando de forma significativa a atmosfera desses locais, provocando, como uma de suas diversas conseqüências, mudanças nas características climáticas do meio, afetando a qualidade de vida de seus habitantes e distanciando os mesmos de uma relação harmoniosa com o ambiente natural.

A condição de desconforto nos ambientes urbanos tem condicionado uma série de prejuízos econômicos, sociais e de qualidade de vida às comunidades urbanas. No caso específico da qualidade climatológica, notam-se significativas diferenças entre os dados climáticos do ambiente urbano comparado com o rural, ou seja, o clima nas cidades sofre influência do conjunto complexo da estrutura urbana. Contudo, essa qualidade climática nas cidades pode ser alcançada se considerarmos os parâmetros físicos para o ambiente urbano juntamente com os dados ambientais (PEZZUTO, 2007).

Dentre os fatores que caracterizam o clima de uma região destacamos os climáticos globais e os fatores climáticos locais. Os fatores climáticos globais determinam e dão origem ao clima em seus aspectos gerais, tais como radiação solar, temperatura, umidade do ar, precipitação, dentre outros. Elementos como a localização geográfica, topografia, vegetação e superfície do solo caracterizam os fatores climáticos locais, que interferem e originam os diversos microclimas encontrados nos centros urbanos.

De acordo com Peixoto (1995), Castro (1999) e Bueno (2003), no ambiente urbano, o conforto térmico vem sendo ameaçado pelas alterações climáticas decorrentes das mudanças das características térmicas das superfícies, das taxas de evaporação, da grande impermeabilização do solo decorrentes de construções e pavimentações, aumento da concentração de poluentes, fruto das atividades humanas, novos padrões de circulação do ar e principalmente devido à ausência de vegetação, causando uma incidência direta da radiação solar nas construções, que retorna ao meio externo sob a forma de calor; este, por sua vez, tem sua dissipação reduzida devido às condições do ambiente, transformando as cidades em verdadeiras estufas, tendo como efeito denunciador o surgimento das chamadas ilhas de calor. O fenômeno das ilhas de calor é caracterizado por importantes 
variações espaciais e temporais relacionadas à topografia, layout e condições do clima (SANTAMOURIS, 2001).

Em um estudo sobre as ilhas de calor na cidade de São Paulo, observou-se que a grande diferença entre os valores de temperatura tomados na área central da cidade e nas áreas periféricas devem-se ao fato da existência, na primeira, de intensa verticalização de suas construções, grande tráfego de veículos - contribuindo para emissão de poluentes na atmosfera - e pouca vegetação (LOMBARDO, 1985).

Com relação aos aspectos relacionados ao conforto humano em espaços abertos Lois e Labaki (2001) relatam que as atividades, tanto ativas quanto passivas dos habitantes urbanos, necessitam de ambientes que sejam confortáveis termicamente. Neste contexto que se pode considerar o emprego da arborização nesses espaços, a qual de acordo com Mello Filho (1985) desempenha funções essenciais e apresentam como suas principais funções:

- Função química: absorção do gás carbônico e liberação do oxigênio, melhorando a qualidade do ar urbano;

- $\quad$ Função física: as copas das árvores oferecem sombra, proteção térmica e absorvem ruídos;

- $\quad$ Função paisagística: quebra da monotonia da paisagem pelos diferentes aspectos e texturas decorrentes de suas mudanças estacionais;

- Função ecológica: as árvores oferecem abrigo e alimento aos animais, protegem e melhoram os recursos naturais (solo, água, flora e fauna) e especificamente para árvores dispostas nos sistemas viários tem a função de atuarem como corredores que interligam as demais modalidades de áreas verdes (MILANO, 1987) e;

- $\quad$ Função psicológica: arborização é fator determinante da salubridade mental, por ter influência direta sobre o bem estar do ser humano, além de proporcionar lazer e diversão.

Mas é no controle da temperatura do ambiente, atenuando grande parte da radiação incidente, que as árvores, em grupos ou mesmo isoladas desempenham seu papel mais importante, pois, conforme Furtado (1994), a vegetação propicia resfriamento passivo principalmente por dois meios:

1) Através do sombreamento lançado pela vegetação, que reduz a conversão de energia radiante sensível, conseqüentemente reduzindo as temperaturas de superfície dos objetos sombreados e;

2) Através do consumo da energia para a evapotranspiração na superfície da folha, resfriando a folha e o ar adjacente dado à troca de calor latente, ou seja, a 


\section{Emprego da Arborização...}

vegetação retira calor do meio e o transforma e não armazena calor como ocorre nos materiais de construção.

Neste contexto, torna-se fundamental a manutenção e/ou implantação de áreas verdes urbanas, com o propósito de mitigar o desconforto térmico sofrido pelos cidadãos nos espaços livres públicos, lugares estes onde se busca a socialização e a prática de lazeres sadios e atividades para o bem estar. A utilização efetiva desses espaços se dará em virtude das condições de conforto que os mesmos oferecem e, com base nestes aspectos, o presente trabalho tem por objetivo demonstrar a importância da arborização urbana no contexto dos espaços livres públicos, com a finalidade de proporcionar aos mesmos, condições de conforto térmico e, conseqüentemente, efetividade em sua utilização em função de sua influência na qualidade de vida dos cidadãos.

\section{O espaço livre público e a qualidade de vida}

A cidade é o meio que, substituído ao ecossistema natural, permitiu a sobrevivência do ser humano, sendo o espaço livre público destinado ao uso coletivo onde são realizadas diversas atividades, tornando-se um local onde as pessoas convivem interagindo com este novo meio (GASPARINI JR. \& FONTES, 2002).

Conforme Coltro e Miranda (2007), o espaço urbano é considerado basicamente por espaços construídos - áreas edificadas compostas por casas, comércio e indústrias, áreas destinadas à circulação da população tais como o sistema rodo-ferroviário, e áreas não edificadas, definidas como "espaços livres de construção" (LIMA et al., 1994), assim como o são em outros países como nos de língua inglesa, onde são denominados como open space (JELICOE \& JELICOE, 1996; Mc HARG ,1969); nos de língua alemã, como Freiraum (RICHTER, 1981); e, nos de língua castelhana, como espacios libres (Mc HARG, 2000), que são termos mais amplos e explicitam funções que desempenham, e que, ainda na década de 60 do século passado, foram considerados como áreas monitorada para a produção ou preservação de recursos naturais, para o incremento da saúde, bem-estar, conforto e segurança pública.

Dentro dos diversos tipos de espaços livres públicos, pode-se classificá-los, segundo Robba e Macedo (2004) em espaços de valor estético/simbólico, ambiental e recreativo. Espaços com valor estético e simbólico caracterizam-se por um alto grau de referência à população ou ainda por ser um apelo turístico. O valor ambiental atribuído a alguns espaços caracteriza-se pela preservação e proteção de elementos naturais, também sendo associadas às possibilidades de estudos, pesquisas, entre outros, favorecendo ainda, a melhoria de ventilação e aeração urbana, dispersão de poluentes, insolação em áreas muito adensadas, controle de temperatura, drenagem pluvial, proteção do solo contra erosões, 
proteção e valorização de cursos d'água. E, o valor recreativo, associado às possibilidades funcionais do espaço.

Versando sobre este assunto, Lois e Labaki (2001) colocam que, as atividades que os espaços livres públicos podem abrigar podem ser de caráter ativo ou passivo, ou seja, praticadas de forma consciente ou inconsciente. Atividades ligadas à recreação e ao passeio, usufruindo os melhores horários são consideradas ativas. $E$ as passivas determinam-se pela ausência de escolha do usuário. As atividades ativas realizadas nos espaços livres públicos também são, em muitas vezes, determinadas pelas condições microclimáticas dos espaços, geradas pela presença ou não de vegetação, água e de mobiliário urbano.

Os espaços livres podem ser divididos em: áreas livres privadas, potencialmente coletivas ou públicas. Sendo denominados espaços livres de uso público, as áreas cujo acesso da população é livre. Entre os espaços livres, temos assim as áreas verdes, onde há o predomínio de vegetação arbórea, e que englobam as praças, os jardins públicos, os parques urbanos, os canteiros centrais e trevos de vias públicas, todos com função estética e ecológica (LIMA et al., 1994).

Segundo Robba e Macedo (2002), as áreas verdes, especificamente as praças, sempre foram celebradas como um espaço de convivência e lazer dos habitantes urbanos. E, como citado em Macedo e Sakata (2002), acredita-se que uma cidade com mais espaços públicos abertos e com oferta de áreas de recreação para a comunidade propiciam um estilo urbano mais agradável. A população das cidades sempre sente necessidade destes espaços, onde possa encontrar um cenário tranqüilo que tenha a ação de um antídoto contra as pressões e as tensões do trabalho.

Gangloff (1996) também ressalta a importância das árvores e áreas verdes urbanas para a qualidade de vida nas cidades. Segundo ele, estas áreas valorizam o ambiente e a estética, além de promoverem um excelente meio para as atividades da comunidade, criando importantes espaços e oportunidades de recreação e educação. Estas áreas também atraem investimentos, turismo e geram empregos, além de representarem uma fonte sustentável de matéria prima.

Uma boa qualidade destes espaços deve favorecer a permanência prazerosa e tranqüila dos usuários, possibilitando o desenvolvimento de atividades sociais e conseqüentemente a vitalidade urbana. Contudo, alguns fatores físicos e ambientais podem influenciar negativa ou positivamente na qualidade desses espaços, o que está de forma interligada a qualidade de vida da população, uma vez que a convivências sociais e experiências coletivas se concretizam nesses espaços.

Segundo Rosset (2005), duas questões fundamentais devem ser consideradas quando se analisa a qualidade de vida. A primeira tem a ver com a necessidade dos 


\section{Emprego da Arborização...}

indivíduos estarem relacionados com o contexto social, político e cultural em que vivem, e a segunda, está relacionada com a caracterização de um espaço em termos de bens e serviços existentes, bem como sua acessibilidade e facilidade de utilização.

Dentre alguns indicadores que expressam a qualidade do ambiente de uma cidade quando se trata de vegetação urbana de acordo com Nucci (2001) destacam-se: o índice de áreas verdes (IAV) que expressa à relação entre a quantidade de área verde $\left(\mathrm{m}^{2}\right)$ e a população que vive em determinada cidade, e o índice de cobertura vegetal (ICV) que representa a relação entre a cobertura arbórea $\left(\mathrm{m}^{2}\right)$ e a população, sem distinção entre as tipologias de vegetação (OLIVEIRA, 1996). Considerando somente as áreas verdes públicas localizadas na zona urbana e ligadas ao uso direto da população residente na área urbana (NUCCl, 2001).

De acordo com Rosset (2005), em termos gerais, a estimativa da qualidade da vegetação ou de áreas verdes per capita, permite inferir sobre os aspectos de qualidade de vida da população. Diversos autores também enfatizam a importante influência do desenho dos espaços públicos, nos seus termos relacionados ao tipo de superfície, geometria do espaço, a presença ou não de vegetação, dentre outros, no sentido de qualificar o espaço público.

Outros autores citam a condição microclimática como um dos aspectos determinante para a qualificação dos espaços livres públicos, e que também pode interferir na quantidade e forma de uso dos mesmos, sendo decisivo no que se refere à percepção dos benefícios que esses espaços proporcionam à qualidade de vida da população, sendo eles Boussoualim e Legendre (2001); Fontes e Delbin (2001); Fontes e Gasparini Jr. (2003); Fontes e Murata (2004).

Katzschner (2003), através de um projeto de pesquisa europeu, analisou o comportamento das pessoas nos espaços livres públicos em função das condições microclimáticas urbanas. O projeto avaliou diferentes regiões climáticas européias. As variáveis climáticas foram combinadas com as entrevistas realizadas, em diferentes estações do ano, com o objetivo de estudar a influência do comportamento das pessoas em condições térmicas diferentes. O estudo concluiu que o comportamento dos indivíduos, em espaços abertos, é influenciado pelo efeito da radiação solar e da velocidade do vento. Independentemente da ocasião, as pessoas preferem situações de calor moderado, equilibrados pelas vestimentas. Somente em situações muito quentes as pessoas indicam o vento como fator positivo para se refrescar e sempre preferem áreas sombreadas para realização de suas atividades. 


\section{As árvores e as condições climáticas no contexto urbano}

O crescimento contínuo e desordenado das cidades brasileiras tem ocasionado negligência quanto à composição arbórea de suas vias e locais públicos, gerando assim impactos notáveis no microclima urbano. O desenho urbano, a geometria formada pelas construções, as propriedades físicas dos materiais e o calor antropogênico contribuem intensamente para a alteração microclimática e logo, para a formação das ilhas de calor (DOULOS \& SANTAMOURIS, 2004).

Segundo Bernatzky (1982), as massas de edificações verticais e horizontais, a absorção de calor pelas ruas e prédios, a redução da velocidade dos ventos, a impermeabilização do solo, a redução da energia utilizada nos processos de evapotranspiração dos vegetais devido à diminuição da vegetação, a poluição do ar reduzindo a radiação de onda longa, são fatores que contribuem para a formação de ilhas de calor no ambiente urbano. Assim, os materiais que configuram o desenho urbano e a ausência de vegetação vêm alterando profundamente as características climáticas dos centros urbanos.

Barbirato (1998) analisou o ambiente térmico urbano da cidade de Maceió/AL. Os dados de seu trabalho foram coletados através de medições de temperatura em três áreas distintas da cidade, com diferentes configurações de uso e ocupação do solo. Os resultados mostraram que as áreas edificadas apresentaram efeitos de elevação na temperatura do ar. Também se constatou, com este trabalho, que as temperaturas das áreas urbanas foram superiores às temperaturas da estação meteorológica, utilizada como ponto de referência para o estudo, comprovando a influência da urbanização no clima local.

Outro estudo, realizado por Santana e Lombardo (1997), verificou a relação de uso do solo, forma urbana e diferenças de temperatura do ar na cidade de Fortaleza/CE, neste mediu-se a temperatura do ar, umidade relativa do ar, temperatura radiante do meio, velocidade e direção dos ventos. Os resultados mostraram que a zona com maior densidade de ocupação de veículos e pessoas apresentou, durante o dia, as temperaturas do ar mais elevadas. E as zonas com presença de vegetação e corpos d'água significativos, e à beira mar, apresentaram as temperaturas do ar mais baixas.

As árvores representam um elemento chave para um desenho adequado às exigências de conforto. A vegetação possui uma importante função na melhoria e estabilidade microclimática devido à redução das amplitudes térmicas, redução da insolação direta, ampliação das taxas de evapotranspiração e redução da velocidade dos ventos (MILANO \& DALCIN, 2000).

Duarte e Maitelli (1999) também realizaram medições de temperatura e umidade relativa do ar na superfície, em alguns pontos fixos da cidade de Cuiabá/MT. O objetivo da pesquisa foi detectar a correlação entre o uso e ocupação do solo e as variáveis de conforto 


\section{Emprego da Arborização...}

térmico. Os resultados mostraram diferenças de temperaturas de até $6^{\circ} \mathrm{C}$ entre os pontos de baixa ocupação e as áreas densamente construídas. Ainda, constatou-se que a área mais aquecida é o centro da cidade e as mais secas são aquelas que apresentam alto índice de pavimentação.

Bertacchi e Faria (2005), em seus estudos, analisaram a distribuição da temperatura do ar na cidade de Bauru/SP. Foram empregados dados de um levantamento preliminar de temperatura do ar, em uma série de pontos distribuídos pela cidade. De acordo com a pesquisa, a área central apresentou maior aquecimento que as demais áreas, confirmando a influência do uso de solo, do adensamento de construções e da configuração do desenho urbano. A presença de vegetação foi o aspecto mais importante na análise das diferenças de temperatura entre as diversas áreas.

Dentre os benefícios da vegetação urbana, destaca-se ainda, além de sua importância para o controle climático, o controle da poluição do ar e acústica, melhoria da qualidade estética, efeitos sobre a saúde mental e física da população, aumento do conforto ambiental, valorização de áreas para convívio social, valorização econômica das propriedades e formação de uma memória e do patrimônio cultural (OLIVEIRA, 1996).

Corroborando os resultados encontrados por diversos autores, pode-se citar o estudo que analisou a contribuição da vegetação no conforto térmico nas cidades foi realizado por Bartholomei e Labaki (2002), em Campinas/SP. Nesta pesquisa, analisou-se a função da vegetação na atenuação da radiação solar, contribuindo para a melhoria do conforto térmico. Foi analisada a influência de seis espécies arbóreas em relação ao conforto térmico. A pesquisa concluiu que o índice de conforto varia ao longo do dia e que as espécies, através das diferentes atenuações da radiação, apresentam um índice de conforto diferente. Observou-se também que as espécies que apresentaram o melhor índice de conforto são aquelas que proporcionam maior extensão de sombra sob sua copa.

De Kauffman, Machado e Barroso (2001) realizaram um estudo para avaliação de conforto em áreas abertas de clima quente úmido, na cidade de Maracaibo, Venezuela. Os resultados constataram que a vegetação, especialmente árvores de grande porte, representa um importante papel na modificação e amenização climática. Os benefícios provenientes das árvores dependem diretamente de sua espécie, tamanho da copa, permeabilidade, maturidade e qualidade da sombra.

De acordo com Olgyay (1973) apud Ayres et al (2005) o sombreamento se constituí num dos elementos fundamentais para a obtenção de conforto em climas tropicais. No ambiente urbano as espécies de grande porte são mais eficientes no controle e minimização dos efeitos do clima, se comparadas com a atuação das espécies de menor porte. A temperatura do ar é amenizada pela vegetação através do controle da radiação e pela umidade que é liberada pelo vegetal através de suas folhas. 
Sob o aspecto da influência das áreas verdes no conforto ambiental, Fontes e Delbin (2001) desenvolveram um estudo com o objetivo de comparar e analisar os microclimas em dois espaços públicos abertos na cidade de Bauru/SP. Um dos espaços foi caracterizado com expressiva área verde e o outro com pouca arborização, a fim de analisar a influência da vegetação na amenização climática local. O resultado da pesquisa constatou diferenças climáticas significativas entre os dois espaços, resultando temperaturas de até $3^{\circ} \mathrm{C}$ menor, na área arborizada, em horários de temperatura elevada e em tempo estável. A pesquisa também detectou que, além de contribuir para melhoria das condições climáticas, os espaços verdes promovem a intensificação dos seus usos por serem mais agradáveis ao convívio humano. Esta pesquisa também foi realizada em outros espaços públicos abertos da mesma cidade, comprovando os efeitos benéficos da presença de arborização e equipamento urbano nestes espaços (FONTES et al., 2005).

De acordo com Possebon et al.(1999), se por um lado, é inegável o valor acrescentado à qualidade de vida quando se arboriza uma cidade por outro lado, a inserção desses vegetais no meio urbano não é tão simples, já que esse meio não é o habitat mais apropriado para as plantas. Portanto, arborizar uma cidade exige de seus administradores muita responsabilidade e bom senso, ou seja, requer um planejamento, pois fazê-lo sem critérios pode trazer prejuízos tanto ao poder público quanto à população.

Apesar da grande importância das florestas urbanas, e da realização de trabalhos significativos quantificando os benefícios obtidos a partir das mesmas, poucas cidades brasileiras possuem planejamento efetivo para arborização de suas vias e espaços públicos. Além disso, o Brasil carece de uma política nacional de arborização urbana, que estabeleça as diretrizes para esse planejamento. E como conseqüência perde-se a eficácia da arborização em transmitir conforto às pessoas (SILVA FILHO \& BORTOLETO, 2005).

As árvores são a forma vegetal mais característica da paisagem urbana, seja locada em vias públicas, parques ou áreas privadas, tem-se incorporado a elas estreita relação com a arquitetura ao longo da história, criando uma ambiência urbana agradável. Exatamente por este motivo, deve-se pensar seriamente no desenho dos jardins urbanos, para que eles possam influenciar no microclima das cidades e melhorar a qualidade de vida dos cidadãos.

Atualmente o conceito de arborização urbana tem dado lugar a um conceito mais abrangente, é uma nova área do saber denominada "silvicultura urbana" ou também "verde urbano", que tem como objetivo o cultivo e manejo de árvores para contribuírem ao bemestar fisiológico, sociológico e econômico da população. (RACHID, 1999) 
Emprego da Arborização...

\section{CONCLUSÃO}

Nota-se que o estudo e a documentação dos efeitos das áreas vegetadas sobre o clima das cidades são importantes mecanismos para prover um melhor esclarecimento sobre a importância da arborização nas cidades. A comprovação de sua vantajosa presença no ambiente urbano, favorecendo o conforto térmico, e ainda desempenhando funções tais como: visão paisagística, melhorias ecológica e psicológica à população, corrobora que seu emprego em espaços livres públicos traz benefícios consideráveis a esses espaços, os quais desempenham uma função ímpar na qualidade de vida das comunidades.

Além da evolução do traçado urbano, a forma dos espaços públicos que estão atrelados a este parcelamento, é importante observar que ao implantar a arborização na malha urbana temos benefícios evidentes na melhoria da qualidade de vida da população, favorecendo a intensificação do uso e funções nestes espaços, uma vez que as preferências para realização das atividades se voltam para as condições de áreas arborizadas.

A problemática relacionada à arborização nas cidades, com a produção capitalista dos espaços urbanos, ignora e desrespeita o conforto a ser gerado pela adequada implantação deste sistema, onde o aconchego e utilização efetiva devem ser priorizados.

Apesar de muitos trabalhos demonstrarem a importância das árvores urbanas, não se pode perceber uma atenção focada para este assunto nas políticas públicas dos centros urbanos, pois apesar de sua grande relevância, poucas cidades brasileiras possuem um planejamento efetivo para arborização de suas vias e espaços públicos, mesmo porque o Brasil carece de uma política nacional específica para o referido setor, que venha estabelecer diretrizes norteadoras para sua gestão, perdendo-se assim sua eficácia.

\section{AGRADECIMENTOS}

Os autores agradecem aos seus orientadores, Profa. Dra. Ana Maria Liner Pereira Lima e Prof. Dr. Almir Sales, ao querido Prof. Dr. Demóstenes Ferreira Silva Filho, e são também gratos a CAPES, FAPESP e ao MCT/CNPq.

\section{REFERÊNCIAS BIBLIOGRÁFICAS}

ARAUJO, B. C. D; CARAM, R. Análise ambiental: estudo bioclimático urbano em centro histórico. Ambiente \& Sociedade - Vol. IX nº , 2006. p. 149-167. 
AYRES, M.C.R.; TARGA, L.A.; PEIXOTO, P.P.P. Influência do Sombreamento Natural de Sibipiruna (Caesalpinia peltophoroides) na temperatura de edificações. Energia Agrícola. Botucatu, vol.20, n.1, 2005. p. 62-76.

BARBIRATO, G. M. Aplicação do modelo de balanço de energia para a análise do ambiente térmico Urbano de Maceió, AL. 1998. Tese (Doutorado em Ciências da Engenharia Ambiental) - Escola de Engenharia de São Carlos da Universidade de São Paulo. 173p. São Carlos/SP.

BARTHOLOMEI, C. L. B; LABAKI, L. C. Environmental parameters and thermal comfort provided by different tree species. In.: $19^{\text {th }}$. International Conference on Passive and Low Energy Architecture, 2002. France. Anais...France, 2002. p. 341-344.

BERNATZKY, A. The contribution of trees and green spaces to a town climate. In.: Energy and Buildings, Vol. 5, 10p., 1982. p. 1-10.

BERTACCHI, M. L.; FARIA, J. R. G. Ilhas de calor na cidade de Bauru (SP): as diferenças de temperatura e a configuração do solo local. In.: Encontro Nacional de Conforto no Ambiente Construído, VIII; Encontro Latino-Americano sobre Conforto no Ambiente Construído, IV. 2005. Maceió. Anais... Maceió: ANTAC, 2005. p. 646-652.

BOUSSOUALIM, A.; LEGENDRE, A. A Influence of microclimate characteristics on the use of outdoor public spaces: a study in the city of Blagnac. In.: Encontro Nacional de Conforto no Ambiente Construído, V; Encontro Latino-Americano sobre Conforto no Ambiente Construído, II, 1999. Fortaleza. Anais... Fortaleza: ANTAC, 2001. p. 173 -182.

BUENO, C. L. A influência da vegetação no conforto térmico urbano e no ambiente construído. Tese (Doutorado em Saneamento e Ambiente) - Faculdade de Engenharia Civil, Universidade Estadual de Campinas. 186 p., Campinas, 2003.

CASTRO, L. L. F. L. Estudo de parâmetros de conforto térmico em áreas verdes inseridas no ambiente urbano. Dissertação (Mestrado em Saneamento e Ambiente) Faculdade de Engenharia Civil, Universidade Estadual de Campinas. 125p., Campinas, 1999. 
Emprego da Arborização...

COLTRO, E. M.; MIRANDA, G. M. Levantamento da arborização urbana pública de Irati PR e sua influência na qualidade de vida de seus habitantes. In.: Revista Eletrônica Lato Sensu, Ano 2, Número 1, 2007. p. 27 - 48.

DE KAUFFMAN, M. G.; MACHADO, M. V.; BARROSO, H. Quantifying incidence of the vegetation on the microclimatic Variables in hot-humid climates: "the cují tree". In: 18TH INTERNATIONAL CONFERENCE ON PASSIVE AND LOW ENERGY ARCHITECTURE - PLEA, Anais... Brasil, 2001. p.577-582.

DOULOS, L. M.; SANTAMOURIS, L. I. Passive cooling of outdoor urban spaces: the role of materials. In.: Solar Energy, Número 77, 2004. p. 231-249.

DUARTE, D. ; MAITELLI, G. T. . Clima Urbano e Planejamento em Regiões Tropicais Continentais. In: V Encontro Nacional de Conforto no Ambiente Construído, 1999, Fortaleza/CE. ANTAC, 1999. CD-ROM.

FONTES, M. S. G. C.; DELBIN, S. A qualidade climática de espaços públicos urbanos. In.: Encontro Nacional de Conforto no Ambiente Construído, VI; Encontro Latino-Americano de Conforto no Ambiente Construído, III, 2001. São Pedro. Anais... São Pedro: ANTAC, 2001. p. 155-158.

FONTES, M. S. G. C.; GASPAPARINI JR., R A. A Influência do microclima no uso de espaços públicos. In.: Encontro Nacional de Conforto no Ambiente Construído, VII; Conferência Latino-Americana sobre conforto e Desempenho Energético de Edificações, III, 2003. Curitiba. Anais... Curitiba: ANTAC, 2003. CD-ROM.

FONTES, M. S. G. C.; GIACOMELI, D. C.; HAMADA, M.; RIBEIRO, M. O.; MURATA, D. M.; FONSECA, E. B. S.; GASPAPARINI JR., R. A.; MELO, L. F. Qualidade dos principais espaços públicos de Bauru-SP. In.: Encontro Nacional de Conforto no Ambiente Construído, VIII; Encontro Latino-Americano sobre Conforto no Ambiente Construído, IV, 2005. Maceió. Anais... Maceió: ANTAC, 2005. CD-ROM.

FONTES, M. S. G. C; MURATA, D. M. Avaliação pós-ocupacional em um espaço público da cidade de Bauru - SP segundo parâmetros de conforto térmico: o caso da Praça Rui Barbosa. Relatório Final (Iniciação Científica) - Faculdade de Arquitetura, Artes e Comunicação, Universidade Estadual Paulista "Júlio de Mesquita Filho". 63p. Bauru, 2004. 
FURTADO, A. E. Simulação e análise da utilização da vegetação como anteparo às radiações solares em uma edificação. Dissertação (Mestrado em Conforto Ambiental) Faculdade de Arquitetura e Urbanismo, Universidade Federal do Rio de Janeiro, 138p., Rio de Janeiro, 1994.

GANGLOFF, D. Urban forestry in the USA. In: Second National Conference on Urban Forestry. USA, K D. Collins, 1996. p. 27-29.

GASPARINI JR., R. A; FONTES, M. S. G. C. Influência das características microclimáticas nos usos de espaços públicos da cidade de Bauru-SP: O caso do Parque Vitória Régia. Relatório Final (Iniciação Científica) - Faculdade de Arquitetura, Artes e Comunicação, Universidade Estadual Paulista "Júlio de Mesquita Filho". 48p. Bauru, 2002. RICHTER, G. Handbuch Stadtgrün Landschatfsarchitektur im städtischen Freiraum. Munique: BLV Verlagsgesellschaft, 1981. 319p.

JELICOE, A. G. \& JELICOE, S. The landscape of man. 3.ed. Londres: Thames and Hudson, 1996. 408p.

KATZSCHNER, L. Urban Bioclimate and open space planning. In Fifth International Conference on Urban Climate, Anais... p. 34-38, Poland, 2003.

PEIXOTO, M. C.; LABAKI, L. C.; SANTOS, R. F. Conforto térmico em cidades: efeito da arborização no controle da radiação solar. In: Encontro Nacional de Tecnologia do Ambiente Construído - ENTAC 95, 1995, Rio de Janeiro, RJ. ENTAC 95, Anais... Rio de Janeiro, RJ : ANTAC, 1995. p. 629-634.

LIMA, A. M. L. P.; CAVALHEIRO, F.; NUCCI, J. C.; SOUSA, M. A. L. B.; FIALHO, N. O.; DEL PICCHIA, P. C. D. Problemas de utilização na conceituação de termos como espaços livres, áreas verdes e correlatos. In.: Congresso Brasileiro sobre Arborização Urbana, II; Encontro Nacional sobre Arborização Urbana, Anais... São Luís: Sociedade Brasileira de Arborização Urbana, 1994. p. 539-553.

LOIS, E.; LABAKI, K. L. C. Conforto térmico em espaços externos: uma revisão. In.: Encontro Nacional de Conforto no Ambiente Construído, VI; Encontro Latino-Americano de Conforto no Ambiente Construído, III, 2001. São Pedro. Anais... São Pedro: ANTAC, 2001. p. 209-212. 
Emprego da Arborização...

LOMBARDO, M.A. Ilhas de calor nas metrópoles: o exemplo da cidade de São Paulo, São Paulo, Hucitec, 1985. 244p.

MACEDO, S. S.; SAKATA, F. G. Parques Urbanos no Brasil. São Paulo: Editora Edusp, $2002-207 p$.

Mc HARG, I. Design with Nature. New York: American Museum of Natural History, 1969. $197 p$.

Mc HARG, I. Projectar con la naturaleza. Barcelona Gustavo Gili, 2000. 197p.

MELLO FILHO, L. E. Arborização urbana. In.: Encontro Nacional sobre Arborização Urbana, I, 1985. Porto Alegre. Anais... Porto Alegre, 1985. p. 45-49.

MILANO, M. S. Planejamento e replanejamento de arborização de ruas. In: ENCONTRO NACIONAL SOBRE ARBORIZAÇÃO URBANA, v.2, 1987, Maringá. Anais... p. 1-8.

MILANO, M. S.; DALCIN, E. C. Arborização de vias públicas. Rio de Janeiro, RJ: Light, 2000. 131p.

NUCCl, J. C. Qualidade ambiental e adensamento urbano. São Paulo: Humanitas/FAPESP, 2001. 150 p.

OLIVEIRA, C. H. Planejamento ambiental na cidade de São Carlos (SP) com ênfase nas áreas públicas e áreas verdes: diagnóstico e propostas. Dissertação (Mestrado em Planejamento Urbano e Ecologia Urbana.) - Centro de Ciências Biológicas e da Saúde, Universidade Federal de São Carlos. 132 p. São Carlos, 1996.

PEZZUTO, C. C. Avaliação do ambiente térmico nos espaços urbanos abertos. Estudo de caso em Campinas, SP. Tese (Doutorado em Arquitetura e Construção) - Faculdade de Engenharia Civil, Arquitetura e Urbanismo da Universidade Estadual de Campinas. 197p. Campinas, SP, 2007.

POSSEBON, M. M.; DIAS, M. P. M.; FLORES, A. R. Plano de arborização urbana do município de Vila Nova do Sul/RS - primeira parte. In.: Encontro Gaúcho de Arborização Urbana, I, 1999. Pelotas. Anais... Pelotas/RS, 1999. p. 57-60. 
RACHID, C. Estudo da eficiência de dois métodos de amostragem de árvores de rua na cidade de São Carlos - SP. Scientia Forestalis. n. 56, dez. 1999. p. 59-68.

ROBBA, F.; MACEDO, S. S. Praças Brasileiras. Estudos Geográficos: Revista Eletrônica de Geografia, Rio Claro, v. 2, jul-dez - 2004. p.87-88.

ROSSET, F. Procedimentos metodológicos para estimativa do índice de áreas verdes públicas. Estudo de caso: Erechim, RS. Dissertação (Mestrado em Ecologia e Recursos Naturais) - Centro de Ciências Biológicas e da Saúde, Universidade Federal de São Carlos. 60 p. São Carlos, 2005.

SANTANA, A. M. S.; LOMBARDO, M. A. O desenho urbano e a climatologia em Fortaleza. In.: Encontro Nacional de Conforto no Ambiente Construído, IV, 1997. Salvador. Anais... Salvador: ENCAC, 1997. p. 143-148.

SANTAMOURIS, M. Ed., Energy and climate in the urban environment. Londres, James \& James, 2001. 402p.

SILVA FILHO, D. F.; BORTOLETO, S. Uso de indicadores de diversidade na definição de plano de manejo da arborização viária de Águas de São Pedro - SP. In: Revista Árvore,Viçosa - MG, v. 29, n. 6, 2005. p. 973-982. 